\title{
The Influence of Training Levels and Surgical Experience on Outcomes after Single-Incision Laparoscopic Appendectomy
}

Jonas Raakow ${ }^{1 *}$, Hans-Georg Liesaus ${ }^{2}$ and Roland Raakow ${ }^{2}$

${ }^{1}$ Department of General, Visceral and Transplantation Surgery, Charité - Universitaetsmedizin Berlin, Germany

${ }^{2}$ Department of General, Visceral and Vascular Surgery, Vivantes Klinikum Am Urban, Berlin, Germany

\begin{abstract}
Background: Single-incision laparoscopic appendectomy (SILA) has become an accepted alternative to conventional multiport laparoscopic appendectomy. Yet, little is known about the impact of operations performed by residents on the outcome of SILA. The aim of the present study was to evaluate the safety and efficacy of SILA performed by younger surgeons.

Methods: All SILA's at a single institution were reviewed and grouped according to the educational level of the operating surgeon: group 1 included residents with no experience in single-incision laparoscopic surgery (SILS) and little experience in multiport laparoscopy, group 2 comprised fellows with experience in multiport laparoscopy but with no experience in SILS, and group 3 consisted of senior surgeons, all of whom were experienced in performing SILS.
\end{abstract}

Results: A total of 176 patients were included. The patients had been operated on by residents $(n=62)$, fellows $(n=21)$, or senior surgeons $(n=93)$. Senior surgeons performed the operation in less time than fellows or residents $(48.7$ vs. 55.4 vs. 53.6 minutes, respectively; $p=0.108$ ). Six patients required conversion to multiport laparoscopy while no patient required conversion to the open procedure. The overall postoperative morbidity was $9.1 \%$, with no significant difference between the three groups $(p=0.536)$. The surgeon's level of surgical education was no statistical risk factor for developing postoperative complications after SILA.

Conclusion: Although operating times were longer for residents and fellows compared to senior surgeons, less surgical experience did not correlate with a greater need for conversion to multiport laparoscopy and was not associated with a higher rate of postoperative complications.

Keywords: Single-incision laparoscopic surgery; Single-port; Appendectomy; SILS; SILA; Resident; Surgical training

\section{Introduction}

Over the last thirty years, laparoscopic appendectomy has gained wide acceptance as the surgical procedure of choice for patients with acute or chronic appendicitis. A shorter hospital stay, earlier return to work and activity, better wound healing, and less postoperative pain are now well known reasons for the transition from laparotomy to laparoscopy. These benefits raise the question as to whether more minimalized surgery would offer patients even greater benefits. Therefore, single-incision laparoscopic surgery (SILS) has raised tremendous interest among surgeons in the last few years, and has emerged as a serious alternative to conventional multiport laparoscopy. Although larger series and extended follow-up analyses are still missing and may well provide valuable additional information regarding postoperative outcomes, several studies have demonstrated the technical feasibility and safety of single-incision laparoscopic appendectomy (SILA) [1-6].

Experienced laparoscopic surgeons were reported to have a short learning curve for SILS. As senior surgeons are becoming increasingly familiar with the technique, it is being incorporated in surgical training as well. Appendectomy is one of the most common surgical procedures performed worldwide [7]. Being one of the most basic laparoscopic procedures in general surgery, it is mainly performed by residents. The influence of resident involvement in surgery and postoperative care is controversially discussed. It is reported to be associated with longer operating times, higher costs, and higher complications rates [8-10]. However, it has also been reported to exert a protective effect on the patients' outcome [11]. Little is known about the effect of residentperformed SILA on intraoperative and postoperative outcomes. The purpose of the present study was to determine resident performance and postoperative outcomes in patients undergoing SILA performed by a resident versus SILA performed by an experienced laparoscopic surgeon.

\section{Material and Methods}

We performed a review of all patients who underwent singleincision laparoscopic appendectomy between July 2009 and January 2014 at Vivantes Klinikum Am Urban in Berlin, Germany. Patients who underwent appendectomy as part of another single-incision laparoscopic procedure were excluded from the study. Patients with primary multiport laparoscopic or open appendectomy were also excluded. Demographic data included age, gender, weight, height, body mass index (BMI), the American Society of Anesthesiologists score (ASA score), preoperative comorbidities, previous abdominal surgery, and laboratory data concerning leukocytes and C-reactive protein (CRP) on admission. Details of surgery included operating time, the need for conversion to multiport laparoscopy or the open procedure and the reasons for conversion, intraoperative findings such

*Corresponding author: Jonas Raakow, Department of General, Visceral and Transplantation Surgery, Charité-Universitaetsmedizin Berlin, Augustenburger Platz 1, 13353Berlin, Germany, Tel: +49-30-450-652387; Fax:+49-30-450-552900; E-mail: jonas.raakow@charite.de

Received April 22, 2015; Accepted July 20, 2015; Published July 27, 2015

Citation: Raakow J, Liesaus H, Raakow R. The Influence of Training Levels and Surgical Experience on Outcomes after Single-Incision Laparoscopic Appendectomy Journal of Surgery [Jurnalul de chirurgie]. 2015; 11(2): 103-106 DOI:10.7438/1584-9341-11-3-3

Copyright: @ 2015 Raakow J, et al. This is an open-access article distributed unde the terms of the Creative Commons Attribution License, which permits unrestricted use, distribution, and reproduction in any medium, provided the original author and source are credited. 
as peritonitis, peritoneal adhesions or other pathological findings (e.g. gynecological reports). Data concerning short-term outcomes included postoperative complications, the need for reintervention, leukocyte count, CRP values on discharge, and the length of hospital stay. All specimens were sent for histological investigation, which included determination of the grade of inflammation.

Patients were divided into three groups, based on the educational level of the surgeon performing the operation. Group 1 included all residents from postgraduate year 1 to 6 with no experience in singleincision laparoscopic surgery and little experience in multiport laparoscopy. Fellows (postgraduate year $>6$ ) were pooled in group 2; these surgeons had experience in multiport laparoscopy but no experience in SILS. Group 3 included three senior surgeons and the head of the department, all of whom were highly experienced laparoscopic surgeons. We started performing SILA in July 2009, at the beginning of the study period, but all surgeons in group 3 had previous experience in the procedure. Taken together, they had performed more than 100 single-incision cholecystectomies until July 2009. All surgeons were grouped according to their level of education at the time of the procedure. At the start of the study in July 2009 Group 1 included 6 residents $(n=2$ in postgraduate year $1, n=2$ in postgraduate year $3, \mathrm{n}=1$ in postgraduate year $4, \mathrm{n}=1$ in postgraduate year 5), Group 2 included 4 fellows and Group 3 included 3 attendings and the head of the department.

The surgical procedure has been described earlier [5,12]. A 15 to $20 \mathrm{~mm}$ incision was performed in the umbilical folds and extended downward to the fascia. A commercial port system (TriPort ${ }^{\mathrm{TM}}$ or Triport $+{ }^{\mathrm{TM}}$; Olympus, Germany) was inserted with the provided insertion device. After diagnostic laparoscopy the appendix was identified and detached. Dissection of the mesoappendix was performed using stepwise electrocauterization and scissors. The appendiceal base was both ligated with two Endoloops (Serag Binder; Serag Wiessner, Germany) and cut in-between, or dissected using a stapler system (Endo Gia ${ }^{\mathrm{TM}}$; Covidien, USA). The specimen was removed directly through the port system. The fascia was closed using non-absorbable 0 suture and absorbable 4-0 monofilament sutures for skin closure. Only standard straight 5 to $10 \mathrm{~mm}$ instruments and laparoscopes were used.

The patients' data were entered prospectively into a Microsoft Access (Office 2003, Microsoft, USA) database and reviewed retrospectively. Statistical analysis was performed using SPSS Version 22 (IBM, USA). To compare the three groups, the Chi-square test $(\chi 2)$ was used for analysis of categorical variables, and Student's t-test or a single factor variance analysis for continuous data, with the level of significance set to a $p$ value lower than 0.05 . A logistic regression analysis was performed to assess the educational level of the surgeon as a potential risk factor for postoperative complications after SILA.

\section{Results}

During the study period, 176 patients were identified as having undergone single-incision laparoscopic appendectomy. Patients were divided into three groups: those operated on by residents $(n=62)$, by fellows $(n=21)$ and those operated on by senior surgeons $(n=93)$. The patients' demographic data are shown in Table I. Their mean age was $26.8 \pm 9.2$ years (range, $13-64$ years) and $29.5 \%$ were male. The patients' mean BMI was $22.6 \pm 3.3 \mathrm{~kg} / \mathrm{m}^{2}$ (range, $14.1-32.0 \mathrm{~kg} / \mathrm{m}^{2}$ ), demographic data did not differ significantly between the three groups.

The overall mean operating time was $51.2 \pm 17.2$ minutes (range, 22-140 minutes). The mean operating time required by senior surgeons was $48.7 \pm 17.2$ minutes, followed by residents ( $53.6 \pm 15.7$ minutes) and fellows ( $55.4 \pm 20.5$ minutes), but the difference did not achieve statistical significance $(p=0.108)$. Neither the direct comparison between residents and senior surgeons $(p=0.075)$, nor between residents and fellows ( $p=0.663$ ) or between fellows and senior surgeons $(p=0.119)$ revealed a significant difference in mean operating times (Table II).

Six patients (3.4\%) required conversion to the multiport laparoscopic procedure with insertion of one or two additional trocars. Four conversions (66.7\%) were performed by residents, one by fellows, and one by senior surgeons $(p=0.068)$. The reasons for conversion were extensive peritoneal adhesions, appendix perforation with intraabdominal abscess, or retraction difficulties because of abnormal location of the appendix. No conversion to the open procedure was required.

Complication rates were similar in the three groups $(6.5 \%, 14.3 \%$ and $9.7 \%$, respectively; $p=0.536$ ). The overall postoperative morbidity was $9.1 \%$. No wound infection occurred in patients operated on by residents, two infections among those operated on by fellows, and three in the senior surgeon group. Gastrointestinal complaints included postoperative diarrhoea, bowel obstruction, and intestinal atony or paralysis. Other complications were prolonged postoperative pain, urinary tract infection, and urinary retention. A logistic regression analysis to assess predictors of complications after SILA revealed no significance in respect of the surgeon's educational level on postoperative morbidity (Table III).

Table I: Demographic Data of Patients who underwent SILA $(n=176)$.

\begin{tabular}{|c|c|c|c|c|}
\hline & $\begin{array}{c}\text { Resident } \\
\mathrm{n}=62\end{array}$ & $\begin{array}{c}\text { Fellow } \\
n=21\end{array}$ & $\begin{array}{c}\underset{n}{\text { Senior Surgeon }} \\
n=93\end{array}$ & $p$ value \\
\hline Gender & \multicolumn{4}{|c|}{0.145} \\
\hline Male & $24(28.7 \%)$ & $3(14.3 \%)$ & $25(26.9 \%)$ & \\
\hline Female & $38(61.3 \%)$ & $18(85.7 \%)$ & $68(73.1 \%)$ & \\
\hline ASA-score & \multicolumn{4}{|c|}{0.427} \\
\hline 1 & $51(82.3 \%)$ & $19(90.5 \%)$ & $81(87.1 \%)$ & \\
\hline II & $11(17.7 \%)$ & $2(9.5 \%)$ & $12(12.9 \%)$ & \\
\hline Age (years) & $26.6 \pm 10.4$ & $27.1 \pm 8.2$ & $26.9 \pm 8.6$ & 0.964 \\
\hline BMI $\left(\mathrm{kg} / \mathrm{m}^{2}\right)$ & $22.8 \pm 3.3$ & $22.4 \pm 2.1$ & $22.6 \pm 3.3$ & 0.902 \\
\hline Comorbidities & $13(21.0 \%)$ & $3(14.3 \%)$ & $12(13.3 \%)$ & 0.217 \\
\hline Previous abdominal surgery & $2(3.2 \%)$ & $1(4.8 \%)$ & $7(7.9 \%)$ & 0.228 \\
\hline Leukocytes on admission (nl) & $11.2 \pm 4.2$ & $12.0 \pm 4.7$ & $12.5 \pm 4.3$ & 0.187 \\
\hline Leukocytes on discharge (nl) & $7.3 \pm 2.0$ & $7.1 \pm 1.3$ & $6.8 \pm 1.9$ & 0.354 \\
\hline CRP on admission $(\mathrm{mg} / \mathrm{l})$ & $30.7 \pm 44.9$ & $28.7 \pm 38.4$ & $25.9 \pm 43.5$ & 0.797 \\
\hline CRP on discharge $(\mathrm{mg} / \mathrm{l})$ & $43.9 \pm 46.7$ & $47.9 \pm 45.4$ & $44.1 \pm 36.8$ & 0.925 \\
\hline Length of hospital stay (days) & $3.6 \pm 1.2$ & $3.8 \pm 1.8$ & $3.8 \pm 2.9$ & 0.766 \\
\hline
\end{tabular}

ASA (American Society of Anesthesiologists); BMI (body mass index); CRP (C-reactive protein)

Values are given as numbers and percentages, or means \pm standard deviation 
Table II: Details of Surgery and Histology of Patients who underwent SILA ( $n=176)$.

\begin{tabular}{|c|c|c|c|c|}
\hline & $\begin{array}{l}\text { Resident } \\
n=62\end{array}$ & $\begin{array}{c}\text { Fellow } \\
n=21\end{array}$ & $\begin{array}{c}\text { Senior Surgeon } \\
n=93\end{array}$ & $p$ value \\
\hline Operating time (minutes) & $53.6 \pm 15.7$ & $55.4 \pm 20.5$ & $48.7 \pm 17.2$ & 0.108 \\
\hline Peritonitis & $2(3.2 \%)$ & 0 & $4(4.3 \%)$ & 0.672 \\
\hline Peritoneal adhesions & $5(8.1 \%)$ & $2(9.5 \%)$ & $11(11.8 \%)$ & 0.446 \\
\hline Additional intraoperative findings & $2(3.2 \%)$ & $2(9.5 \%)$ & $9(9.7 \%)$ & 0.14 \\
\hline Conversion to multiport & $4(6.5 \%)$ & $1(4.8 \%)$ & $1(1.1 \%)$ & 0.068 \\
\hline Postoperative complications & $4(6.5 \%)$ & $3(14.3 \%)$ & $9(9.7 \%)$ & 0.536 \\
\hline Wound infection & 0 & $2(9.5 \%)$ & $3(3.2 \%)$ & \\
\hline Intraabdominal abscess/ hematoma & 0 & 0 & $3(3.2 \%)$ & \\
\hline Gastrointestinal complaints & $2(3.2 \%)$ & 0 & $1(1.1 \%)$ & \\
\hline Other & $2(3.2 \%)$ & $1(4.8 \%)$ & $2(2.2 \%)$ & \\
\hline Reoperation & 0 & $1(4.8 \%)$ & $3(3.2 \%)$ & 0.209 \\
\hline Pathology & & & & 0.23 \\
\hline Normal appendix & $4(6.5 \%)$ & $1(4.8 \%)$ & $5(5.4 \%)$ & \\
\hline Acute appendicitis & $47(75.8 \%)$ & $20(95.2 \%)$ & $80(86.0 \%)$ & \\
\hline Chronic appendicitis & $11(17.7 \%)$ & 0 & $8(8.6 \%)$ & \\
\hline Perforation & $4(6.5 \%)$ & $3(14.3 \%)$ & $5(5.4 \%)$ & 0.719 \\
\hline
\end{tabular}

Values given as numbers and percentages, or means \pm standard deviation

Table III: Predictor of postoperativ complications after SILA $(n=16 ; 9.1 \%)$.

\begin{tabular}{|l|c|c|c|}
\hline \multicolumn{1}{|c|}{ OR } & $\mathbf{9 5 \%} \mathbf{~ C l}$ & p value \\
\hline Surgeon level & \multicolumn{3}{|c|}{0.472} \\
\hline Resident & \multicolumn{3}{|c|}{ Referent } \\
\hline Fellow & 1.55 & $0.46-5.29$ & \\
\hline Attending & 2.42 & $0.49-11.82$ & \\
\hline
\end{tabular}

OR (odds-ratio); $\mathrm{Cl}$ (confidence interval)

The median duration of hospital stay for all patients who underwent SILA was 3 days (range, 2-27 days). The mean length of the hospital stay for patients operated on by residents, fellows and senior surgeons was 3.6 $\pm 1.2,3.8 \pm 1.8$ and $3.8 \pm 2.9$ days, respectively $(p=0.766)$.

Figure 1 shows the increasing percentage of operations performed by residents over the last few years. In 2009 and 2010, the first cases of SILA at our institution were mainly operated on by senior surgeons, but in the following years the procedure was performed by younger surgeons.

\section{Discussion}

The aim of the present study was to evaluate the influence of surgical training levels on surgical and postoperative outcomes after single-incision laparoscopic appendectomy, and to ascertain the safety of resident involvement. Reviewing the results of 176 single-incision cases, we found that the surgeon's training level had little impact on outcomes after SILA. Although operating times were longer for residents and fellows compared to senior surgeons, the difference did not achieve statistical significance. A lower surgical training level did not correlate with a greater need for conversion to multiport laparoscopy, and was not associated with a higher rate of postoperative complications, including wound infection, intra-abdominal abscess, hematoma and gastrointestinal complaints.

In previous studies, the involvement of residents in surgery was found to be associated with longer operating times and higher postoperative morbidity for multiport laparoscopic surgery or open surgical procedures in general surgery $[8-10,13]$. We have a limited body of data concerning the presence and impact of surgical trainees on single-incision laparoscopic procedures. In a retrospective analysis of 220 consecutive patients undergoing single-incision laparoscopic cholecystectomy, Sato et al. found residents to be an independent risk factor for prolonged operating times [14]. In a single-port simulator model of Conway et al., experienced single-port surgeons performed surgery faster and with no loss of accuracy compared to experienced conventional laparoscopic and novice laparoscopic surgeons [15].
These reports concur with our data. In the present study, the mean operating time required by senior surgeons with previous experience in single-incision surgery was shorter than that required by fellows or residents, although the difference did not achieve significance. The fellows involved in the study did have prior experience in advanced multiport laparoscopic procedures, but their median operating time was similar to the time required by residents. These difficulties of conventional laparoscopic proficient surgeons to translate these skills to SILS have also been reported by three laboratory-based studies comparing laparoscopic- and SILS-trained candidates [16-18]. Pucher et al. concluded that the skills required for SILS are not automatically acquired through multiport laparoscopic experience [19].

Previous studies showed a steep learning curve for SILS: 10 to 40 attempts were needed to learn single-incision cholecystectomy [19], and about 10 cases to learn single-incision appendectomy [2]. These data were confirmed in our review of the surgeons involved in the present study, but we were unable to determine the exact number of operations needed to achieve a learning curve plateau for singleincision appendectomies. Since previous simulation and training in the skills laboratory were found to enhance a surgeon's skills in multiport laparoscopic surgery, the same could be true for SILS. Simulator training and specific training in SILS might even shorten the learning curve while the patient's comfort could be improved by using a new surgical procedure [20-22]. Therefore, some authors advocate specific SILS training and simulation models $[19,23]$. However, it should be noted that certain surgical skills and procedures can only be learned in the operating room [8].

We do not provide a special SILS simulator model at our institution and do not yet have a SILS-specific training curriculum for residents. All SILS novices in the present study were trained on the job. Using a logistic regression model, we were unable to demonstrate resident or fellow involvement in single-incision appendectomy as a potential risk factor for developing a postoperative complication. The present study confirms that, with appropriate supervision, single-incision surgery performed by surgeons with various levels of education is safe for patients.

The present study is one of the largest single-institution series of SILA, but the number of cases is still small and the study is therefore most likely underpowered. The consequence of the small sample size is a fairly high chance for a Type II error especially regarding our results of the postoperative outcome. The study should therefore only be seen as a pilot study and larger multicentre series and randomization will be 
Residents $\quad$ Fellows $\quad$ Senior surgeons

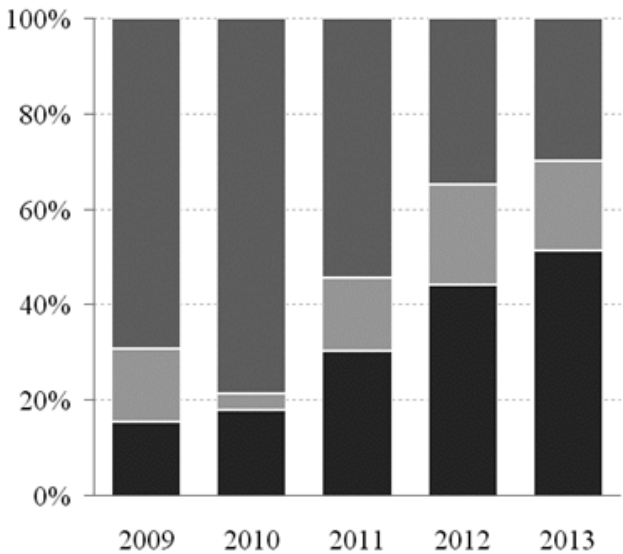

Figure 1: Operations Performed by Residents over the Last Few Years.

needed to validate the findings. Another limitation of the present study is that data concerning the extent of intraoperative resident involvement were not available and were not standardized. In open appendectomy, an experienced surgeon supervising an assistant may significantly influence the speed of the surgical procedure and its outcome. When teaching the laparoscopic procedure, the assisting senior surgeon's role is mainly limited to giving instructions and directing the camera. Thus, the surgical flow and the outcome of surgery is largely dependent on the less experienced operating surgeon. On the other hand, when a resident experiences intraoperative difficulties in performing a laparoscopy, the more experienced fellow or senior surgeon may completely take over and perform the major steps of the operation. As this aspect is rarely documented after an operation, some single-incision appendectomies may have been categorized incorrectly in the present study. This, obviously, is more likely to occur when a resident is involved.

\section{Conclusion}

Patients may rest assured that younger surgeons can perform single-incision laparoscopic appendectomies safely and effectively, although the operating time may be longer and larger case series will be needed to validate the findings. This fact is valuable in view of the paucity of surgeons in Western countries and the fact that education in surgery takes a considerable amount of time.

\section{Conflict of interests}

The authors declared no potential conflicts of interest with respect to the research, authorship, and publication of this article.

\section{References}

1. Buckley FP 3rd, Vassaur H, Monsivais S, Jupiter D, Watson R, et al. (2010) Single-incision laparoscopic appendectomy versus traditional three-port laparoscopic appendectomy: an analysis of outcomes at a single institution. Surg Endosc 28: 626-630.

2. Cho MS, Min BS, Hong YK, Lee WJ (2011) Single-site versus conventional laparoscopic appendectomy: comparison of short-term operative outcomes. Surg Endosc 25: 36-40.

3. Frutos MD, Abrisqueta J, Lujan J, Abellan I, Parrilla P (2013) Randomized prospective study to compare laparoscopic appendectomy versus umbilical single-incision appendectomy. Ann Surg 257: 413-418.

4. Lee WS, Choi ST, Lee JN, Kim KK (2013) Single-port laparoscopic appendectomy versus conventional laparoscopic appendectomy: a prospective randomized controlled study. Ann Surg 257: 214-218.

5. Raakow R, Jacob DA (2011) Initial experience in laparoscopic single-port appendectomy: a pilot study. Dig Surg 28: 74-79.

6. Teoh AY, Chiu PW, Wong TC, Wong SK, Lai PB, et al. (2011) A case-controlled comparison of single-site access versus conventional three-port laparoscopic appendectomy. Surg Endosc 25: 1415-1419.
7. Addiss DG, Shaffer N, Fowler BS, Tauxe RV (1990) The epidemiology of appendicitis and appendectomy in the United States. Am J Epidemiol 132: 910 925.

8. Advani V, Ahad S, Gonczy C, Markwell S, Hassan I (2012) Does resident involvement effect surgical times and complication rates during laparoscopic appendectomy for uncomplicated appendicitis? An analysis of 16,849 cases from the ACS-NSQIP. Am J Surg 203: 347-351.

9. Babineau TJ, Becker J, Gibbons G, Sentovich S, Hess D, et al. (2004) The "cost" of operative training for surgical residents. Arch Surg 139: 366-369.

10. Scarborough JE, Bennett KM, Pappas TN (2012) Defining the impact of resident participation on outcomes after appendectomy. Ann Surg 255: 577-582.

11. Raval MV, Wang X, Cohen ME, Ingraham AM, Bentrem DJ, et al. (2011) The influence of resident involvement on surgical outcomes. J Am Coll Surg 212: 889-898.

12. Raakow J, Liesaus HG, Neuhaus $P$, Raakow R (2015) Single-incision versus multiport laparoscopic appendectomy: a case-matched comparative analysis. Surg Endosc 29: 1530-1536.

13. Davis SS Jr, Husain FA, Lin E, Nandipati KC, Perez S, et al. (2013) Resident participation in index laparoscopic general surgical cases: impact of the learning environment on surgical outcomes. J Am Coll Surg 216: 96-104.

14. Sato N, Yabuki K, Shibao K, Mori Y, Tamura T, et al. (2014) Risk factors for a prolonged operative time in a single-incision laparoscopic cholecystectomy. HPB (Oxford) 16: 177-182.

15. Conway NE, Romanelli JR, Bush RW, Seymour NE (2014) Ramifications of Single-Port Laparoscopic Surgery: Measuring Differences in Task Performance Using Simulation. Surg Innov 21: 106-111.

16. Alevizos L, Brinkman W, Fingerhut A, Jakimowicz J, Leandros E (2012) Novice surgeons versus experienced surgeons in laparoendoscopic single-site (LESS) surgery: a comparison of performances in a surgical simulator. World J Surg 36: 939-944

17. Santos BF, Enter D, Soper NJ, Hungness ES (2011) Single-incision laparoscopic surgery (SILS) versus standard laparoscopic surgery: a comparison of performance using a surgical simulator. Surg Endosc 25: 483-490.

18. Santos BF, Reif TJ, Soper NJ, Hungness ES (2011) Effect of training and instrument type on performance in single-incision laparoscopy: results of a randomized comparison using a surgical simulator. Surg Endosc 25: 3798 3804.

19. Pucher PH, Sodergren MH, Singh P, Darzi A, Parakseva P (2013) Have we learned from lessons of the past? A systematic review of training for single incision laparoscopic surgery. Surg Endosc 27: 1478-1484.

20. Gurusamy KS, Aggarwal R, Palanivelu L, Davidson BR (2009) Virtual reality training for surgical trainees in laparoscopic surgery. Cochrane Database Syst Rev CD006575.

21. Schijven MP, Jakimowicz JJ, Broeders IA, Tseng LN (2005) The Eindhoven laparoscopic cholecystectomy training course--improving operating room performance using virtual reality training: results from the first E.A.E.S. accredited virtual reality trainings curriculum. Surg Endosc 19: 1220-1226.

22. Scott DJ, Bergen PC, Rege RV, Laycock R (2000) Laparoscopic training on bench models: better and more cost effective than operating room experience? J Am Coll Surg 191: 272-283.

23. Miller S, Causey MW, Damle A, Maykel J, Steele S (2013) Single-incision laparoscopic colectomy: training the next generation. Surg Endosc 27: 1784-1790. 